\title{
Germinação e desenvolvimento inicial in vitro de explantes de araçá- vermelho
}

\author{
Germination and initial in vitro development of explants of red strawberry-guava \\ Samila Silva Camargo, Aline Meneguzzi, Lediane Bisol, Gabriela Maciel Paiano, Maicon Magro, \\ Leo Rufato
}

Universidade do Estado de Santa Catarina, Lages, SC. Brasil. *Autor para correspondência: samilasc@yahoo.com.br

\begin{abstract}
RESUMO
Entre as fruteiras nativas do Sul do Brasil, destaca-se o araçazeiro vermelho (Psidium cattleyanum Sabine) da família Myrtaceae e por isso, é considerado uma espécie florestal nativa de grande importância nessa região. O araçazeiro é propagado normalmente por via sexuada, entretanto são poucos os estudos que otimizem a propagação desta espécie nativa. Aliado a isso, para contornar esta problemática, muitos estudos com espécies florestais lenhosas demonstram resultados positivos com a propagação por meio de técnicas de cultura de tecidos. Dessa forma, o objetivo foi verificar a germinação in vitro de araçazeiro vermelho, assim como, o desenvolvimento inicial dos explantes com o uso da técnica de micropropagação. Utilizou-se um delineamento inteiramente casualizado, com arranjo fatorial 3 $x 2$, sendo três formas de fracionamento de sementes (sem corte, longitudinal e transversal) e duas condições de intensidades luminosas (presença de luz e obscuridade), totalizando seis tratamentos com 10 repetições de quatro sementes cada. Após 14 dias da instalação do experimento, as variáveis analisadas foram: oxidação (\%) e estiolamento (\%) e transcorridos 240 dias, avaliou-se a taxa germinativa das sementes $(\%)$, comprimento médio de raízes $(\mathrm{cm})$, da maior raiz $(\mathrm{cm})$ e do explante $(\mathrm{cm})$ e número de raízes e de folhas. Concluiu-se com esse estudo, que uma única semente de Psidium cattleyanum Sabine, ao ser fracionada, mantêm a capacidade germinativa e pode produzir mais de uma plântula normal, a fim de ter-se assim, uma quantidade maior de mudas, a partir de um número reduzido de sementes. Além disso, foi verificado que independentemente do fracionamento ou não das sementes de araçazeiro vermelho, condições diretas de luz proporcionaram raízes de maior comprimento, assim como, um maior número de folhas nos explantes.
\end{abstract}

PALAVRAS-CHAVE: Psidium cattleyanum Sabine, sementes, micropropagação, luminosidade, escuro, fracionamento.

\begin{abstract}
Among the native fruit trees of the South of Brazil, the red strawberry guava (Psidium cattleyanum Sabine) of the Myrtaceae family and it is considered a native forest species of great importance in this region. The strawberry guava is usually propagated through sexual reproduction, however, few studies have been done to optimize the propagation of this native species. In addition to this problem, many studies with woody plants have shown positive results with propagation through tissue culture techniques. In this way, the objective was to verify the in vitro germination of red strawberry guava and the initial development of the explants with the use of the micropropagation technique. A completely randomized design with $3 \times 2$ factorial arrangement was used, with three forms of seed fractionation (without cutting, longitudinal and transverse cutting) and two conditions of light intensities (presence and absence of light), totaling six treatments with 10 replications of four seeds each. After 14 days of the experiment were evaluated oxidation (\%) and sowing $(\mathrm{cm})$. The seeds germination rate $(\%)$, mean root length $(\mathrm{cm})$, length of the largest root $(\mathrm{cm})$, length of explant and number of roots and leaves were analyzed with 240 days. It was concluded that just a single seed of Psidium cattleyanum, when being fractionated, maintains the germinative capacity and can produce more than one normal seedling, in order to have a larger number of seedlings, from a smaller number of seeds. In addition, it was verified that regardless of the fractionation or not of the red spider seeds, direct light conditions provided roots of greater length, as well as a larger number of leaves in the explants.
\end{abstract}

KEYWORDS: Psidium cattleyanum Sabine, seeds, micropropagation, luminosity, dark, fractionation. 


\section{INTRODUÇÃO}

Entre as fruteiras nativas do Sul do Brasil, destaca-se o araçazeiro vermelho (Psidium cattleyanum Sabine) da família Myrtaceae, no qual apresenta grande potencial de uso em pomares comerciais (DANNER et al. 2010, TOMAZ et al. 2011) e representa uma extensa área de ocorrência na costa Atlântica, encontrando-a desde a Bahia até o nordeste do Uruguai (FRANZON et al. 2009). Segundo KROLOW \& AQUINI (2010), o araçá, juntamente com a pitanga, uvaia, feijoa e butiá podem contribuir para o desenvolvimento sustentável da agricultura familiar, atendendo a diferentes nichos de mercado, com utilização na agroindústria e na indústria farmacêutica.

Os frutos do araçazeiro podem ser comercializados para atender ao mercado in natura ou as indústrias, na forma de doces em pastas, cristalizados ou geleias, pois possuem um elevado valor nutricional, baixo teor de açúcar, presença de vitamina C e compostos fenólicos (SANTOS et al. 2007, ALTOÉ et al. 2011). Além disso, outras características estão sendo descobertas, como o uso do composto de óxido $\beta$-cariofileno presente nas folhas para o combate a células cancerígenas (JUN et al. 2011), que podem potencializá-la ainda mais, servindo de incentivo para aqueles que buscam nichos de mercado (HOSSEL et al. 2017a).

Outro destaque para a espécie $P$. cattleyanum é a possibilidade de uso como porta-enxerto para goiabeira $(P$. guajava) $\mathrm{cv}$. Paluma quando se deseja resistência a nematóides, pois apresenta resistência a Meloidogyne mayaguensis (CARNEIRO et al. 2007).

Visto que a maioria das espécies florestais nativas são propagadas por sementes, o sucesso na formação de mudas depende do conhecimento do processo germinativo da espécie e da semente utilizada (REGO et al. 2009). No caso específico do araçazeiro, são necessários estudos que visem a aceleração e uniformização da germinação das sementes, a fim de verificar as possibilidades de serem propagados como cultivares comerciais (TOMAZ et al. 2011). O araçazeiro é considerado uma espécie de difícil propagação vegetativa e o método de propagação mais utilizado é o seminal (DONADIO et al. 2007), uma vez que, inicialmente a propagação vegetativa por estaquia não havia demonstrado resultados promissores (FACHINELLO et al. 1993, NACHTIGAL \& FACHINELLO 1995), com exceção a trabalhos mais recentes em que os autores obtiveram porcentagens altas, em torno de $92 \%$, de enraizamento de miniestacas de araçazeiro (ALTOÉ et al. 2011).

A produção de plantas matrizes predominantemente pelo uso das sementes torna-se vantajosa pelo fato da muda oriunda desse processo apresentar período juvenil curto, além deste método de propagação apresentar maior facilidade de manuseio e ao rendimento do número de mudas que se pode obter de um único fruto (HOSSEL et al. 2017b). Para $P$. cattleyanum são encontrados na literatura relatos de que a propagação por semente apresenta pouca variabilidade, provavelmente pelo fato de que boa parte das sementes é produzida por apomixia (FRANZON et al. 2009).

Contudo, para contornar esta problemática, muitos estudos com espécies florestais lenhosas demonstram resultados positivos com a propagação por meio de técnicas de cultura de tecidos (SOUZA et al. 2006, XAVIER et al. 2007).

A micropropagação é uma técnica que pode ser usada para a produção de um elevado número de mudas em curto espaço de tempo, além de favorecer a qualidade fitossanitária, devido às condições controladas do ambiente (CAMARGO et al. 2015). Dentre estas condições ambientais, a luminosidade é um fator importante pois existe uma ampla variação nas respostas germinativas devido a sensibilidade luminosa das sementes (MENEZES et al. 2004) que também podem interferir no desenvolvimento inicial do explante. Além disso, SILVA et al. (2003) destacam que o fracionamento de sementes de Eugenia pyriformis, tentando maximizar o uso destas na produção de mudas, possibilita obter mais de uma plântula normal por semente.

Nesse sentido, em outras espécies nativas, também da família Myrtaceae, as características anatômicas e a origem de novas plântulas a partir desse embrião, quando fracionado, vêm sendo amplamente estudadas (JUSTO et al. 2007, DELGADO et al. 2010), assim como, a influência da luz, a qual exerce grande influência na germinação, sendo o embrião responsável pela percepção e tradução do estímulo luminoso (KOLLER 1972).

Objetivou-se estudar a influência da luminosidade assim como, cortes nas sementes de araçazeiro vermelho (Psidium cattleyanum Sabine), a fim de favorecer o processo de germinação e crescimento dos explantes in vitro.

\section{MATERIAL E MÉTODOS}

O experimento foi realizado no Laboratório de Micropropagação Vegetal, pertencente ao Centro de 
Ciências Agroveterinárias /Universidade do Estado de Santa Catarina (CAV/UDESC, Lages, SC). O mesmo foi instalado no mês de março de 2016, em delineamento inteiramente ao acaso, onde os tratamentos estudados foram dois fatores distintos, fracionamento das sementes (sem corte, corte longitudinal e corte transversal) e também, condições luminosas (luz e escuro), totalizando seis tratamentos, em um arranjo fatorial $3 \times 2$, com 10 repetições cada, sendo cada repetição com quatro sementes.

As sementes de araçazeiro foram coletadas de uma única planta, localizada na cidade de Lages, SC, a fim de manter a homogeneidade e evitar variações entre diferentes plantas matrizes e foram mantidas em temperatura ambiente, de aproximadamente $23 \pm 2 \stackrel{\circ}{\circ}$, por 24 horas. Posteriormente, as sementes foram desinfestadas em câmara de fluxo laminar, imersas em álcool $70 \%$ sob agitação por 30 segundos e em seguida, imersão em hipoclorito de sódio na concentração de $2,5 \%$ de cloro ativo, com adição de duas gotas de Tween $20^{\circledR}$, durante 15 minutos. Na sequência, o material desinfestado passou por tríplice lavagem em água destilada e autoclavada.

As sementes foram cultivadas em meio de cultura MS (MURASHIGE \& SKOOG 1962), com a metade da concentração de sais $(1 / 2 \mathrm{MS})$ e além dos sais e vitaminas característicos deste meio de cultivo, foram adicionados $100 \mathrm{mg} \mathrm{L}^{-1}$ mio-inositol e $30 \mathrm{~g} \mathrm{~L}^{-1}$ sacarose. $\mathrm{O} \mathrm{pH}$ foi ajustado para 5,8 antes da inclusão do ágar na concentração de $6,0 \mathrm{~g} \mathrm{~L}^{-1}$ e posteriormente, realizou-se a autoclavagem dos frascos de $200 \mathrm{~mL}$ de capacidade de volume, com $30 \mathrm{~mL}$ meio de cultura, a $121^{\circ} \mathrm{C}$ e $\mathrm{kgf} \mathrm{cm}^{-2}$ de pressão, por 20 minutos.

Para a execução dos diferentes tratamentos, as sementes foram fracionadas em dois sentidos (longitudinal e transversal) com uma lâmina de bisturi em câmara de fluxo laminar antes da inoculação em meio de cultura e como controle, foram utilizadas sementes sem fracionamento, onde foram mantidas intactas. E em relação ao ambiente de desenvolvimento, as sementes mantidas em luz, foram transferidas imediatamente após a inoculação no meio de cultivo, para sala de crescimento, com condições controladas, fotoperíodo de 16 horas, temperatura de $25 \pm 2{ }^{\circ} \mathrm{C}$ e intensidade luminosa de $27 \mu \mathrm{mol} \mathrm{m} \mathrm{m}^{-2} \mathrm{~s}^{-1}$ e as sementes mantidas no escuro, permaneceram em caixas de papelão lacradas, totalmente isoladas de radiações de luz, sob um período de 21 dias e posteriormente, mantidas nas condições idênticas ao tratamento com a presença de luz.

Após 21 dias da instalação do experimento, as variáveis analisadas foram: oxidação (\%) e estiolamento (\%) e transcorridos 240 dias, avaliou-se a taxa germinativa das sementes (\%), comprimento médio de raízes $(\mathrm{cm})$, da maior raiz $(\mathrm{cm})$ e do explante $(\mathrm{cm})$ e número de raízes e de folhas. Os dados foram submetidos à análise de variância e as médias pelo teste de Tukey com $5 \%$ de probabilidade de erro, sendo os valores em porcentagem transformados em [(arco seno $\left.\sqrt{ } \mathrm{x}) \cdot 100^{-1}\right]$, e os provenientes de contagem em $\sqrt{ }(x+0,5)$, onde $x$, em ambos os casos, é o dado obtido de cada variável.

\section{RESULTADOS E DISCUSSÃO}

Para as variáveis oxidação das sementes e estiolamento, ocorreu interação entre ambos os fatores estudados, ao nível de $5 \%$ de probabilidade de erro, a partir do teste de Tukey (Tabela 1).

Tabela 1. Oxidação (\%) e estiolamento (\%) no estabelecimento in vitro de sementes de araçazeiro vermelho. Lages, SC, 2017.

Table 1. Oxidation (\%) and waving (\%) in the in vitro establishment of red strawberry-guava seeds. Lages, SC, 2017.

\begin{tabular}{lccccc}
\hline & \multicolumn{3}{c}{ Oxidação (\%) } & \multicolumn{2}{c}{ Estiolamento (\%) } \\
\hline Luz & Escuro & Luz & Escuro \\
Sem corte & $2,57 \mathrm{Aa}^{*}$ & $1,73 \mathrm{Ab}$ & $1,00 \mathrm{Ab}$ & $2,28 \mathrm{Ba}$ \\
Transversal & $1,78 \mathrm{Ca}$ & $1,68 \mathrm{Aa}$ & $1,00 \mathrm{Ab}$ & $2,57 \mathrm{Aa}$ \\
Longitudinal & $2,26 \mathrm{Ba}$ & $1,26 \mathrm{Ba}$ & $1,00 \mathrm{Ab}$ & $2,57 \mathrm{Aa}$ \\
\hline
\end{tabular}

${ }^{*}$ Médias seguidas de mesma letra minúscula nas linhas e maiúscula nas colunas, dentro de cada tratamento, não diferem entre si pelo teste de Tukey ao nível de $5 \%$.

Como verificado, os maiores problemas com oxidação das sementes de araçá-vermelho, ocorreram quando cultivadas sob condições de luz. Esses resultados corroboram aos obtidos por FREITAS et al. (2009), onde confirmam que a atividade de enzimas relacionadas com a biossíntese e oxidação de fenóis é aumentada pela luz e que o escurecimento é menor em explantes retirados de plantas cultivadas no escuro ou em baixa intensidade luminosas. Os mesmos autores destacam a importância de controle dos níveis de 
escurecimento dos materiais, já que in vitro, a oxidação fenólica constitui um dos principais problemas enfrentados no início do estabelecimento e durante o cultivo de explantes de diferentes espécies.

$\mathrm{Na}$ presença de luz o fracionamento transversal das sementes foi o menos afetado pela oxidação, já as sementes mantidas no escuro, sementes sem corte não diferiram estatisticamente daquelas fracionadas transversalmente $(p<0,05)$.

Claramente os explantes germinados mantidos no escuro, independentemente do tipo de corte nas sementes (transversal ou longitudinal), apresentaram maior estiolamento, do que as que emergiram na presença de luz. Logo, mesmo a taxa de germinação ter sido maior na obscuridade, houve a formação de uma plântula pálida e esguia, com folhas não desenvolvidas, como no estiolamento, assim, não pode realizar a fotossíntese e somente quando expostas à luz, sintetiza clorofila e adquire a cor verde, portanto, 0 processo de estiolamento é indesejável para o crescimento e desenvolvimento das plântulas (SADAVA et al. 2009). Esse crescimento compromete a sustentação da parte aérea, justificando assim a maior fragilidade das plântulas germinadas na ausência de luz, já que as plantas na ausência de luz investem mais em crescimento de caules, porém, não resulta em um ganho real de massa seca visto que as plantas estão apenas respirando e gastando suas reservas (CARVALHO et al. 2009, SILVA et al. 2016).

De acordo com os fatores estudados, o fracionamento de sementes e presença ou ausência de luz, influenciaram isoladamente as variáveis, comprimento dos explantes e da maior raiz $(\mathrm{cm})$ e número de raízes, como demonstrado na Tabela 2, sem ocorrer interação entre os fatores. Porém, para a variável germinação de sementes (\%), não ocorreram diferenças estatísticas entre os tratamentos. Este dado se torna bastante interessante, em função de uma única semente permitir a formação de mais de uma muda. $O$ mesmo foi encontrado por SILVA et al. (2005), onde verificaram que sementes de Eugenia involucrata, uniflora e brasiliensis, fracionadas ao meio, mantiveram a capacidade germinativa e produziram plântulas normais. Entretanto, o resultado deste estudo, difere dos apresentados por SILVA et al. (2003), que constataram que o fracionamento das sementes de $E$. pyriformis pode quase duplicar a porcentagem de germinação.

Tabela 2. Germinação de sementes (\%), comprimento dos explantes e da maior raiz $(\mathrm{cm})$ e número de raízes in vitro de araçazeiro vermelho. Lages, SC, 2017.

Table 2. Seed germination (\%), length of explants and largest root $(\mathrm{cm})$ and number of roots in vitro of red strawberry-guava. Lages, SC, 2017.

\begin{tabular}{lrrrc}
\hline Tratamentos & Germinação & $\begin{array}{c}\text { Comprimento } \\
\text { explante }\end{array}$ & $\begin{array}{c}\text { Comprimento maior } \\
\text { raiz }\end{array}$ & Número de raízes \\
\hline Sem corte & $78^{\mathrm{ns}}$ & $3,64 \mathrm{a}$ & $4,044^{\mathrm{ns}}$ & $2,33 \mathrm{~ns}$ \\
Transversal & $85^{\mathrm{ns}}$ & $2,42 \mathrm{~b}$ & $4,11^{\mathrm{ns}}$ & $2,34^{\mathrm{ns}}$ \\
Longitudinal & $77,5^{\mathrm{ns}}$ & $2,56 \mathrm{~b}$ & $4,044^{\mathrm{ns}}$ & $2,30 \mathrm{~ns}$ \\
Luz & $78^{\mathrm{ns}}$ & $2,77^{\mathrm{ns}}$ & $4,47 \mathrm{a}$ & $2,27 \mathrm{~b}$ \\
Escuro & $80^{\mathrm{ns}}$ & $2,97^{\mathrm{ns}}$ & $3,66 \mathrm{~b}$ & $2,40 \mathrm{a}$ \\
\hline CV $(\%)$ & 16,25 & 16,53 & 12,75 & 5,69
\end{tabular}

*Médias seguidas pela mesma letra na coluna não diferem pelo teste de Tukey com nível de significância de 5\%.

ns: não significativo.

Como demonstrado na Tabela 2, não houveram diferenças entre a presença ou ausência de luz para a variável germinação de sementes. Esse resultado contraria ao encontrado por MARTINOTTO et al. (2007), onde verificaram que a influência da luz, provavelmente, relacionada com a fotodegradação de compostos inibidores presentes no tegumento, aceleraram a germinação. Similarmente, DOUSSEAU et al. (2008) constataram em diferentes temperaturas, que não ocorreu germinação de Plantago tomentosa no escuro, sendo a luz um fator essencial à germinação desta espécie.

Sementes de $P$. cattleyanum apresentam certo atraso para o início do processo germinativo (HOSSEL et al. 2017b), já que ainda não se têm estudos testando-se outras técnicas que poderiam ativar a germinação, sem a necessidade prévia de submissão ao frio, como demonstrado por outros autores como TREVISAN et al. (2004) e TOMAZ et al. (2011). Outros autores destacam ainda, que o balanço dos fitorreguladores (auxinas, citocininas e giberelinas) pode promover ou não o aumento significativo da germinação das sementes de araçazeiro, com a quebra da dormência fisiológica, além do desenvolvimento das plantas (PEIXOTO et al. 2011, TOMAZ et al. 2011, CANESIN et al. 2012, ZANELA et al. 2012, SANTOS Rev. Ciênc. Agrovet., Lages, SC, Brasil (ISSN 2238-1171) 
et al. 2013, HOSSEL et al. 2017b).

O comprimento dos explantes oriundos de sementes não fracionadas foi maior do que aquelas oriundas dos tratamentos de fracionamento (Tabela 2), possivelmente pelo fato que estas não tiveram metade das suas reservas removidas pelos fracionamentos (SILVA et al. 2005). E para esta variável, não houve influência das condições luminosas, no desenvolvimento na luz ou escuro, indicando que possivelmente esta espécie não necessita de luz para esta fase, já que a mesma é necessária para a germinação de algumas espécies (BASKIN \& BASKIN 1998).

Em contrapartida, as variáveis relacionadas ao sistema radicular, comprimento da maior raiz e número de raízes, não foram influenciadas pelo corte nas sementes, e sim, pela presença de luz, onde apresentaram valores superiores aos tratamentos mantidos em condições de obscuridade. $O$ mesmo foi concluído por VICTÓRIO \& LAGE (2009), com estudo de Calendula officinalis L., que constataram que as plântulas obtidas dos testes conduzidos no escuro apresentaram redução significativa em parâmetros do desenvolvimento vegetal, como o enraizamento. Aliado a isso, não somente condições de luminosidade, como também efeitos de tratamentos químicos, favorecem a emissão radicular em determinadas frutíferas (SCALON et al. 2006).

Vale ressaltar, que a não diferenciação entre os fracionamentos das sementes é uma característica de extrema importância. AMADOR \& BARBEDO (2011) concluíram também que espécies de Eugenia têm potencial para regenerar novas raízes e até plantas inteiras, a partir de sementes que tiveram parte de sua massa removida, o que raramente ocorre em sementes, resultado esse, que pode ser usado tecnologicamente para ampliar o potencial de produção de mudas. Com a espécie trabalhada, os mesmos autores, assim como, SILVA et al. $(2003,2005)$, concluíram a dependência da separação das metades da semente para iniciar algum processo de indução de formação de novas mudas e raízes, fato esse, distinto ao obtido no presente estudo, onde para o araçazeiro vermelho, não houveram diferenças para o fracionamento ou não do material seminal.

Para a mesma variável, com os dados apresentados na Tabela 2, verifica-se que o fator luminosidade foi favorável para a emissão de raízes de sementes de araçazeiro, diferentemente aos encontrados por TOMAZ et al. (2011), onde concluíram com outros tratamentos pré-germinativos (diferentes temperaturas e presença de ácido giberélico para quebra de dormência) aos quais foram submetidas às sementes de araçazeiro vermelho e araçazeiro amarelo, que não influenciaram o número de raízes das plântulas.

De acordo com a Tabela 3, verifica-se que para os fatores estudados neste trabalho apresentaram interação para as variáveis comprimento médio de raízes $(\mathrm{cm})$ e número de folhas dos explantes de araçazeiro vermelho. Essa influência entre luminosidade de cultivo $x$ fracionamento de semente, demonstra que tanto as características intrínsecas quanto os fatores ambientais interferem nas respostas de germinação e desenvolvimento, onde, entre eles, a luz é um fator físico que desencadeia sinais internos de ativação ou inativação de vias metabólicas nas sementes e nas plantas (KERBAUY 2008, VICTÓRIO \& LAGE 2009).

Tabela 3. Comprimento médio de raízes $(\mathrm{cm})$ e número de folhas em explantes in vitro de araçazeiro vermelho. Lages, SC, 2017.

Table 3. Average length of roots $(\mathrm{cm})$ and number of leaves in in vitro explants of red strawberry-guava. Lages, SC, 2017.

\begin{tabular}{lccccc}
\hline Tratamentos & \multicolumn{3}{c}{$\begin{array}{c}\text { Comprimento médio } \\
\text { de raízes }\end{array}$} & \multicolumn{3}{c}{$\begin{array}{c}\text { Número } \\
\text { de folhas }\end{array}$} \\
\hline & Luz & Escuro & Luz & Escuro \\
\hline Sem corte & $1,10 \mathrm{Ab}$ & $1,59 \mathrm{ABa}$ & $3,50 \mathrm{Aa}$ & $3,50 \mathrm{Aa}$ \\
Transversal & $1,36 \mathrm{Aa}$ & $1,27 \mathrm{Ba}$ & $3,51 \mathrm{Aa}$ & $2,67 \mathrm{Bb}$ \\
Longitudinal & $1,31 \mathrm{Ab}$ & $1,77 \mathrm{Aa}$ & $3,31 \mathrm{Aa}$ & $3,16 \mathrm{Ab}$ \\
\hline
\end{tabular}

CV $(\%)$

15,31

11,41

*Médias seguidas de mesma letra minúscula nas linhas e maiúscula nas colunas, dentro de cada tratamento, não diferem entre si pelo teste de Tukey ao nível de $5 \%$.

Com base na Tabela 3, para o comprimento médio de raízes, os melhores resultados foram encontrados na presença e ausência de luz, com os cortes transversal e longitudinal, respectivamente. E em relação ao número de folhas, independente da incisão em condições de luz e o não fracionamento das 
sementes mantidas no escuro apresentaram valores superiores. A partir dos dados demonstrados, verificase mais uma vez, que em geral, independente de realização de incisão nas sementes, a luz desempenha papel importante na etapa pós-germinativa dos explantes, já que a fotossíntese não é considerada atividade essencial para o desenvolvimento plantas in vitro, porém, a luz é fundamental para a regulação dos processos morfogenéticos (MURASHIGE 1974).

Em suma, com os resultados apresentados nesse estudo, verifica-se que para essa espécie nativa florestal, araçazeiro vermelho (Psidium cattleyanum Sabine), o fracionamento de sementes é considerado uma técnica viável para a produção de mudas em escala comercial. Tal fato pode representar algum tipo de estímulo à formação de novas raízes, resultante da incisão realizada nas sementes, proporcionando assim, um grande potencial para regeneração de raízes e plântulas, na qual possibilita a produção de mais de uma muda a partir de uma única semente (AMADOR \& BARBEDO 2011).

\section{CONCLUSÃO}

Apenas uma semente de Psidium cattleyanum Sabine, ao ser fracionada, mantêm a capacidade germinativa e pode produzir mais de uma plântula normal, a fim de ter-se assim, uma quantidade maior de mudas, a partir de um número mais reduzido de sementes.

Independentemente do fracionamento ou não das sementes de araçazeiro vermelho, condições diretas de luz proporcionaram raízes de maior comprimento, assim como, um maior número de folhas nos explantes.

\section{AGRADECIMENTOS}

A Coordenação de Aperfeiçoamento de Pessoal de Nível Superior (CAPES) pelo apoio financeiro e ao Centro de Ciências Agroveterinárias/Universidade do Estado de Santa Catarina (CAV/UDESC) pela estrutura e condições fornecidas para a execução do trabalho.

\section{REFERÊNCIAS}

ALTOÉ JA et al. 2011. Propagação de araçazeiro e goiabeira via miniestaquia de material juvenil. Bragantia 70: 312318.

AMADOR TS \& BARBEDO CJ. 2011. Potencial de inibição da regeneração de raízes e plântulas em sementes germinantes de Eugenia pyriformis. Pesquisa Agropecuária Brasileira 46: 814-821.

BASKIN CC \& BASKIN JM. 1998. Seeds: ecology, biogeography, and evolution of dormancy and germination. San Diego: Academic Press. 666p.

CAMARGO SS et al. 2015. Fitorreguladores e espectros de luz na micropropagação de Oncidium baueri Lindl. Ciência Rural 45: 2007-2012.

CANESIN A et al. 2012. Bioestimulante no vigor de sementes e plântulas de faveiro (Dimorphandra mollis Benth.). Cerne 18: 309-315.

CARNEIRO RMDG et al. 2007. Resistance to Meloidogyne mayaguensis in Psidium spp. Accessions and their Grafting Compatibility with $P$. guajava cv. Paluma. Fitopatologia Brasileira 32: 281-284.

CARVALHO CAL et al. 2009. Tópicos em Ciências Agrárias. Cruz das Almas: UFRB. 296p.

DANNER MA et al. 2010. Repetibilidade de caracteres de fruto em araçazeiro e pitangueira. Ciência Rural 40: 20862091.

DELGADO LP et al. 2010. Potential for regeneration and propagation from cut seeds of Eugenia (Myrtaceae) tropical tree species. Seed Science and Technology 38: 624-634.

DONADIO LC et al. 2007. Frutas brasileiras. Jaboticabal: Novos Talentos, 2002. 288p. Espécies Florestais. In: BORÉM, A. (Ed.) Biotecnologia florestal. Viçosa: UFV. p.55-74.

DOUSSEAU $S$ et al. 2008. Germinação de sementes de tanchagem (Plantago tomentosa lam.): influência da temperatura, luz e substrato. Ciência e Agrotecnologia 32: 438-443.

FACHINELLO JC et al. 1993. Efeito do ácido indolbutírico e PVP no enraizamento de estacas de araçazeiro (Psidium cattleyanum Sabine) em diferentes substratos. Revista Brasileira de Fisiologia Vegetal 5: 1990-1993.

FRANZON RC et al. 2009. Araçás do gênero Psidium: principais espécies, ocorrência, descrição e usos. Planaltina:

Embrapa Cerrados. 48p. (Embrapa Cerrados. Documentos, 266).

FREITAS RMO et al. 2009. Efeito dos tratamentos de oxidação em Aloysia virgata. Revista Caatinga 22: 176-179.

HOSSEL $C$ et al. 2017a. Estratificação e ácido indolbutírico na germinação de sementes de araçazeiro vermelho. Revista Brasileira de Tecnologia Agropecuária 1: 52-57.

HOSSEL C et al. 2017b. Tempo e temperatura da pré-secagem pós hidrocondicionamento em sementes de araçazeiro 'Ya-Cy'. Revista Brasileira de Tecnologia Agropecuária 1: 45-51.

JUN NJ et al. 2011. Cytotoxic activity of $\beta$-caryophyllene oxide isolated from Jeju Guava (Psidium cattleyanum Sabine) leaf. Records of Natural Products 5: 242-246.

JUSTO CF et al. 2007. Efeito da secagem, do armazenamento e da germinação sobre a micromorfologia de sementes 
de Eugenia pyriformis Camb. Acta Botânica Brasílica 21: 539-551.

KERBAUY GB. 2008. Fisiologia Vegetal. 2.ed. Rio de Janeiro: Guanabara Koogan. 431p.

KOLLER D. 1972. Environmental control of seed germination. New York: Academic Press. 447p.

KROLOW ACR \& AQUINI D. 2010. Sabor nativo: Inovações e transferência de tecnologia em rede de microempresas e agroindústrias familiares na região de Pelotas-Brasil. In: V Simpósio Nacional do Morango; IV Encontro sobre pequenas frutas e frutas nativas do Mercosul. Palestras e resumos... Pelotas: Embrapa Clima Temperado. p.85-89.

MARTINOTTO C et al. 2007. Efeito da escarificação e luminosidade na germinação in vitro de sementes de cagaiteira (Eugenia dysenterica DC.). Ciência e Agrotecnologia 21: 319-325.

MENEZES NL et al. 2004. Germinação de sementes de Salvia splendens Sellow em diferentes temperaturas e qualidades de luz. Revista Brasileira de Sementes 26: 32-37.

MURASHIGE T \& SKOOG F. 1962. A revised medium for rapid growth and biossay with tabacco tissue cultures. Physiologia Plantarum 15: 473-497.

MURASHIGE T. 1974. Plant propagation through tissue cultures. Annual Review of Plant Physiology 25: 135-166.

NACHTIGAL JC \& FACHINELLO JC. 1995. Efeito de substratos e do ácido indolbutírico no enraizamento de estacas de araçazeiro (Psidium cattleyanum Sabine). Revista Brasileira de Agrociência 1: 34-39.

PEIXOTO CP et al. 2011. Ação da giberelina em sementes pré-embebidas de mamoneira. Comunicata Scientiae 2: $70-$ 75.

REGO SS et al. 2009. Germinação de sementes de Blepharocalyx salicifolius (H.B.K.) Berg. em diferentes substratos e condições de temperatura, luz e umidade. Revista Brasileira de Sementes 31: 212-220.

SADAVA D et al. 2009. Vida: a ciência da biologia. Porto Alegre: Artmed.

SANTOS CAC et al. 2013. Germinação de sementes e vigor de plântulas de maracujazeiro amarelo submetidos à ação do ácido giberélico. Bioscience Journal 29: 400-407.

SANTOS MS et al. 2007. Caracterização do suco de araçá vermelho (Psidium cattleianum Sabine) extraído mecanicamente e tratado enzimaticamente. Acta Scientiarum Agronomy 29: 617-621.

SCALON SPQ et. al. 2006. Germinação e crescimento inicial da muda de orelhas de macaco: efeitos de tratamentos químicos e luminosidade. Revista Árvore 34: 529-536.

SILVA CV et al. 2003. Fracionamento e germinação de sementes de uvaia (Eugenia pyriformis Cambess - Myrtaceae). Revista Brasileira de Botânica 26: 213-221.

SILVA CV et al. 2005. Fracionamento e germinação de sementes de Eugenia. Revista Brasileira de Sementes 27: 8692.

SILVA FJ et al. 2016. Efeito da luz na germinação e desenvolvimento de plântulas de pinhão-manso (Jatropha curcas L.) de distintas procedências. Hoehnea 43: 195-202.

SOUZA JA et al. 2006. Efeito do tipo de ramo e do regime de luz fornecido à planta matriz no estabelecimento in vitro de araçazeiro cv. "Irapuã". Ciência Rural 36: 1920-1922.

TOMAZ ZFP et al. 2011. Tratamentos pré-germinativos em sementes de araçazeiro (Psidium cattleyanum Sabine L.). Revista Brasileira de Agrociência 17: 60-65.

TREVISAN R et al. 2004. Propagação de plantas frutíferas nativas. In: RASEIRA MCB et al.(Eds.). Espécies frutíferas do sul do Brasil. Pelotas: EMBRAPA. p.49- 71.

VICTÓRIO CP \& LAGE CLS. 2009. Germinação e desenvolvimento pós-germinativo in vitro de Calendula officinalis L. sob diferentes qualidades de luz. Revista de Biologia e Farmácia 3: 81-87.

VICTÓRIO CP \& LAGE CLS. 2009. Efeitos da qualidade de luz na germinação e desenvolvimento inicial in vitro de Phyllanthus tenellus. Revista Ciência Agronômica 40: 400-405.

XAVIER A et al. 2007. Micropropagação e enxertia in vitro de espécies florestais, pp. 55-74. In: A. BORÉM (ed). Biotecnologia Florestal. Viçosa: [s.n.].

ZANELA J et al. 2012. Biofilmes e pré-embebição de sementes na germinação do araçazeiro 'Ya-Cy'. Revista Brasileira de Agrociência 18: 229-232. 